Article

\title{
Fe-Chlorophyllin Promotes the Growth of Wheat Roots Associated with Nitric Oxide Generation
}

\author{
Min Tong ${ }^{\dagger}$, Liefeng Zhang ${ }^{\dagger} *$, Yifan Wang, Hui Jiang and Yong Ren * \\ Jiangsu Key Laboratory for Supramolecular Medicinal and Applications, College of Life Science, \\ Nanjing Normal University, Nanjing 210046, China; E-Mails: tongmin@163.com (M.T.); \\ yifan@gmail.com (Y.W.); Jianghui523@163.com (H.J.) \\ $\dagger$ These authors contributed equally to this work. \\ * Authors to whom correspondence should be addressed; E-Mails: 1fzhang@njnu.edu.cn (L.Z.); \\ renyong@njnu.edu.cn (Y.R.); Tel. +86-25-8589-1591; Fax: +86-25-8589-1591.
}

Received: 1 November 2010; in revised form: 7 December 2010 / Accepted: 14 December 2010 / Published: 17 December 2010

\begin{abstract}
Effects of Fe-chlorophyllin on the growth of wheat root were investigated in this study. We found that Fe-chlorophyllin can promote root growth. The production of nitric oxide in wheat root was detected using DAF-2DA fluorescent emission. The intensity of fluorescent in the presence of $0.1 \mathrm{mg} / \mathrm{L} \mathrm{Fe}$-chlorophyllin was near to that observed with the positive control of sodium nitroprusside (SNP), the nitric oxide donor. IAA oxidase activity decreased with all treatments of Fe-chlorophyllin from 0.01 to $10 \mathrm{mg} / \mathrm{L}$. At the relatively lower Fe-chlorophyllin concentration of $0.1 \mathrm{mg} / \mathrm{L}$, the activity of IAA oxidase displayed a remarkable decrease, being $40.1 \%$ lower than the control. Meanwhile, Fe-chlorophyllin treatment could increase the activities of reactive oxygen scavenging enzymes, such as superoxide dismutase (SOD) and peroxidase (POD), as determined using non-denaturing polyacrylamide gel electrophoresis. These results indicate that Fe-chlorophyllin contributes to the growth of wheat root associated with nitric oxide generation.
\end{abstract}

Keywords: Fe-chlorophyllin; nitric oxide; IAA oxidase; SOD; POD 


\section{Introduction}

It is well documented that various stresses lead to the overproduction of reactive oxygen species (ROS) in plants, which are highly reactive and toxic and ultimately result in oxidative stress [1]. In contrast to $\mathrm{O}_{2}$, these partially reduced or activated derivatives of oxygen [singlet oxygen $\left({ }^{1} \mathrm{O}_{2}\right)$, superoxide anion $\left(\mathrm{O}^{2-}\right)$, hydrogen peroxide $\left(\mathrm{H}_{2} \mathrm{O}_{2}\right)$ and hydroxyl radical (HO-)] are highly reactive and toxic, and can lead to the oxidative destruction of cells. Yu and Yang basically implies that progressive aging is associated with increasing steady-state levels of oxidatively modified biomolecules as a result of free radical reactions [2]. However, the mechanism of ROS production and its scavenging is not well known. ROS have been the uninvited companions of aerobic life [3]. Therefore, plants with the ability to scavenge and/or control the level of cellular ROS may be useful in the future to withstand various stresses.

Chlorophyllin (CHL), the sodium-copper salt and the water-soluble analogue of the ubiquitous green pigment chlorophyll, has been attributed to have several beneficial properties. Chlorophyllin, widely studied as a chlorophyll derivative, has been shown to inhibit the mutagenicity of various chemicals [4,5]. Kamat [6] reported that CHL was highly effective in protecting mitochondria, even at a low concentration of $10 \mu \mathrm{M}$. The antioxidant ability, at equimolar concentration, was more than that observed with ascorbic acid, glutathione, mannitol and tert-butanol. Previous reports demonstrated that commercial CHL consists of a few kinds of copper chlorophyll derivatives [7,8]. Among them, two chlorin compounds, copper chlorin $\mathrm{e}_{6}\left(\mathrm{CuCe}_{6}\right)$ and copper chlorin $\mathrm{e}_{4}\left(\mathrm{CuCe}_{4}\right)$, were suggested to be the major components responsible for the antioxidant activity of CHL [7]. This finding presented the possibility that some chlorin derivatives may be potent antioxidants. Yu et al. [8] reported that iron chlorin $\mathrm{e}_{6}\left(\mathrm{FeCe}_{6}\right)$ significantly reduced hydroxyl radical-induced thiobarbituric acid reactive substance (TBARS) formation and benzoate hydroxylation in a dose-dependent manner.

Fe-chlorophyllin is a novel hydroxyl radical scavenger in mammals [8,9], but little is known about the similar mechanisms that may operate in plants. In the present investigation we have examined the effects of Fe-chlorophyllin on the growth of wheat roots. In this study, we found that Fe-chlorophyllin could increase the activities of reactive oxygen scavenging enzyme, enhance intracellular nitric oxide generation and decrease the IAA oxidase activity in roots.

\section{Results and Discussion}

\subsection{Fe-Chlorophyllin Promotes the Growth of Wheat Roots}

To investigate whether Fe-chlorophyllin could promote the growth of wheat roots, wheat seeds were treated with different concentrations of Fe-chlorophyllin. The results in Figure 1 show that Fe-chlorophyllin was effective in promoting the growth of wheat roots in a dose-dependent manner. For example, compared to the control alone, the addition of $0.1 \mathrm{mg} / \mathrm{L} \mathrm{Fe}$-chlorophyllin resulted in an increase of 2.13-fold in the length of wheat roots. However, higher concentrations of Fe-chlorophyllin contributed to inhibition of the growth of wheat roots.

Recently, Liu et al. [10] found that low concentration of hemin stimulated seed germination, while high concentration resulted in an inhibitory effect. Such dual effects of Fe-chlorophyllin were also confirmed in this study. 
Figure 1. Fe-chlorophyllin regulates the root development of wheat (a, b). Seeds of wheat were soaked in distilled water containing various concentrations of Fe-chlorophyllin for $12 \mathrm{~h}$ and then transferred to the quarter-strength Hoagland's nutrient solution containing different concentrations of Fe-chlorophyllin for six days after germination. (a) Photograph of wheat primary root formation; (b) The length of wheat roots. Values represent the mean of three independent experiments and vertical bars indicate standard deviations ( $n=45$ seedlings). Asterisks indicate that mean values are significantly different between the treatment and control $(p<0.05)$.

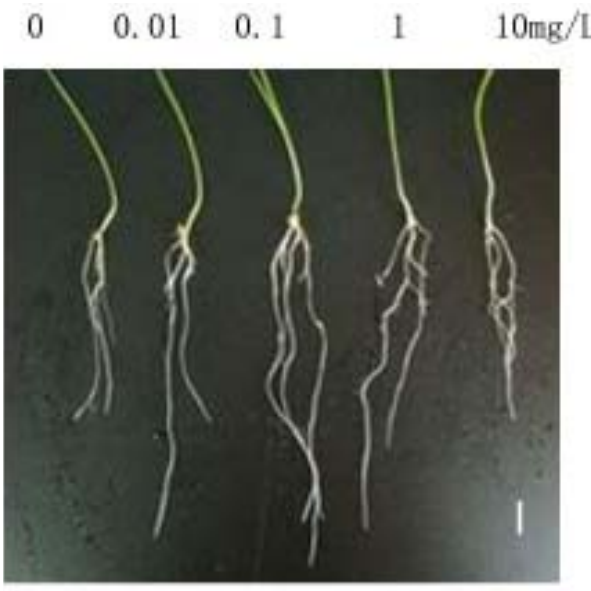

(a)

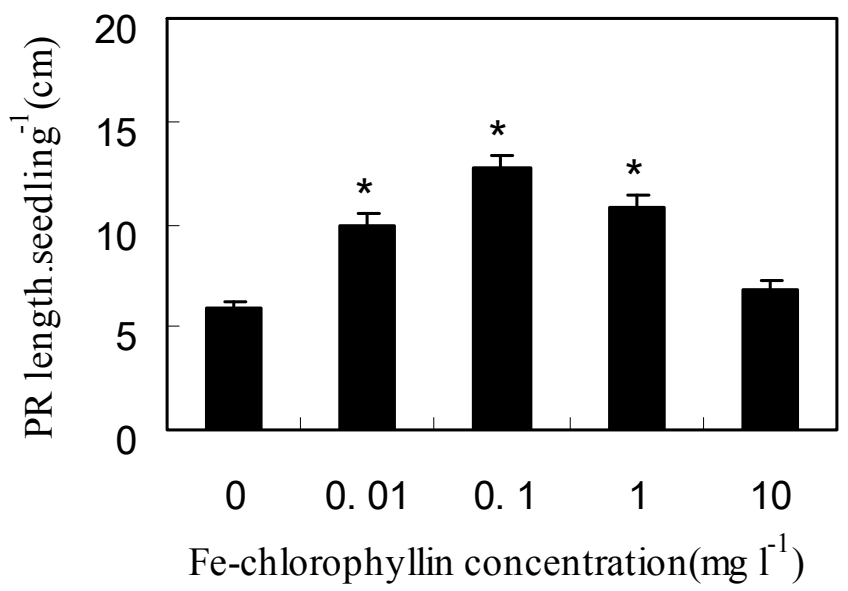

(b)

\subsection{Changes of Anti-Oxidant Enzymes in Response to Fe-Chlorophyllin}

Antioxidant enzymes can scavenge reactive oxygen species (ROS), and ROS initiate several oxidatively destructive processes. In this study, antioxidant enzymes were observed.

Superoxide dismutase (SOD) activity in Fe-chlorophyllin treated root was assayed by native polyacrylamide gel electrophoresis. Five SOD isoforms were detected in the root of wheat (Figure 2a). The patterns of the five isoforms showed different responses to different Fe-chlorophyllin concentrations. Wheat treated with $0.01 \mathrm{mg} / \mathrm{L}$ and $10 \mathrm{mg} / \mathrm{L}$ did not show a significant change in activity of SOD isoforms-II, V. However, treating Fe-chlorophyllin with $0.1 \mathrm{mg} / \mathrm{L}$ and $1 \mathrm{mg} / \mathrm{L}$ caused a remarkable increase in activity of SOD isoforms-II, III, IV, and V. There is a new SOD isoform-I which only appears at the concentration $0.1 \mathrm{mg} / \mathrm{L}$.

Seven bands of peroxidase (POD) isoforms in the root of wheat were detected (Figure 2b). All isoforms of POD appeared to show lower activity in the control, but the activities were enhanced at every Fe-chlorophyllin concentration $(0.01,0.1,1,10 \mathrm{mg} / \mathrm{L})$. Activity of POD isoforms-I, II, III, IV was also stimulated with the increasing concentration of Fe-chlorophyllin up to $0.1 \mathrm{mg} / \mathrm{L}$, where the peak activity was detected. However, activity decreased with $1 \mathrm{mg} / \mathrm{L}$ and $10 \mathrm{mg} / \mathrm{L}$ Fe-chlorophyllin.

The effects of Fe-chlorophyllin on POD and SOD activities in wheat seedling roots were investigated. As shown in Figures $2 \mathrm{c}$ and $2 \mathrm{~d}$, the activities of SOD and POD increased first, and then decreased. There were Fe-chlorophyllin concentration-dependent changes in the activities of SOD and POD. Treatments of seeds with 0.01 to $10 \mathrm{mg} / \mathrm{L}$ of Fe-chlorophyllin stimulated the activities of SOD and POD. However, at the relatively lower Fe-chlorophyllin concentration of $0.1 \mathrm{mg} / \mathrm{L}$, the activities 
of SOD and POD displayed a remarkable increase, being $39.5 \%$ and $65.4 \%$ higher than the control, respectively (Figures 2c, 2d).

Figure 2. Effects of Fe-chlorophyllin on the activities of SOD and POD in the root of wheat. Seeds of wheat were soaked in the same culture solution containing $0,0.01,0.1,1$ and $10 \mathrm{mg} / \mathrm{L}$ Fe-chlorophyllin for $12 \mathrm{~h}$ and then transferred to the quarter-strength Hoagland's nutrient solution containing different concentrations of Fe-chlorophyllin for four days after germination. After that, the treated roots homogenized, and root extracts containing $80 \mu \mathrm{g}$ proteins were subjected to native polyacrylamide gels electrophoresis. The activities of SOD (a) and POD (b) were visualized by staining of gels (see Materials and Methods section). The arrows point to bands corresponding to isoforms. In (c and d), vertical bars represent standard deviation of the mean $(n=3)$. Asterisks indicate that mean values are significantly different between the treatment and control $(p<0.05)$.

SOD

$\begin{array}{lllll}0 & 0.01 & 0.1 & 1 & 10 \mathrm{mg} / \mathrm{L}\end{array}$

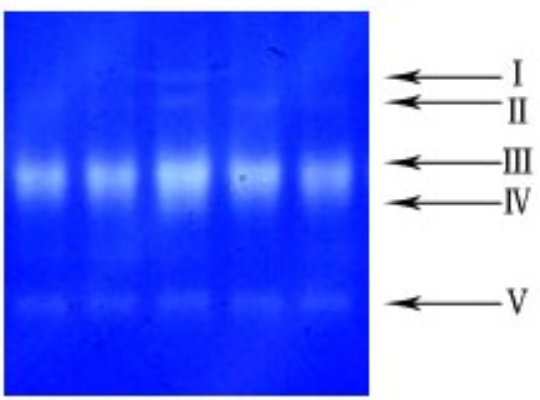

(a)

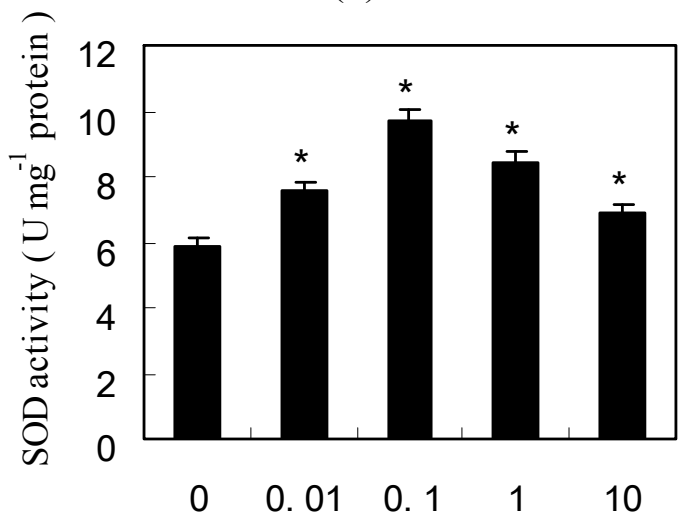

Fe-chlorophyllin concentration $\left(\mathrm{mg} \mathrm{l}^{-1}\right)$

(c)

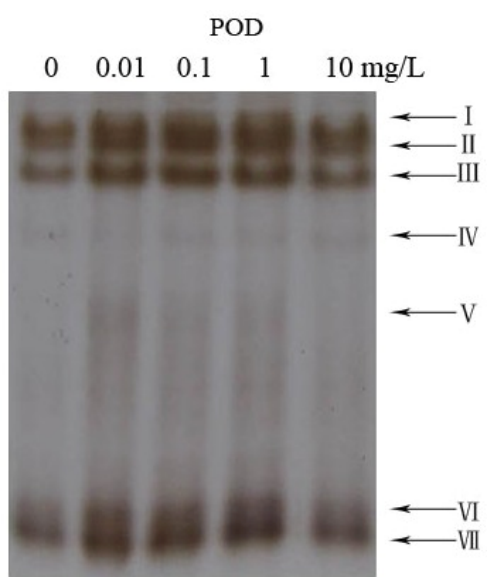

(b)

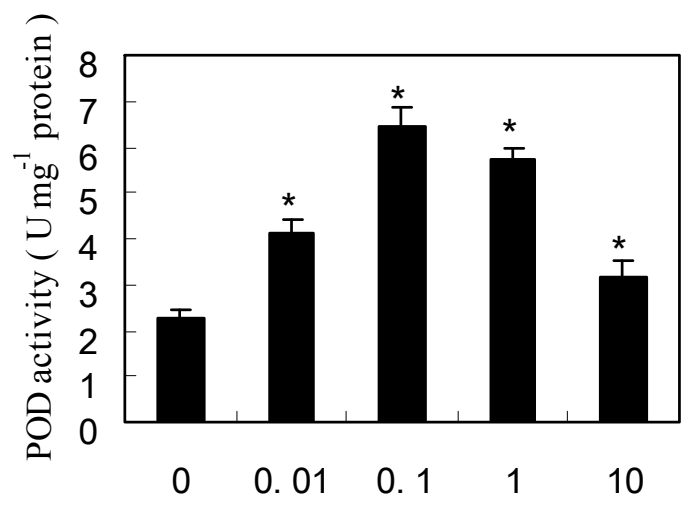

Fe-chlorophyllin concentration $\left(\operatorname{mg~} 1^{-1}\right)$

(d) 


\subsection{Fe-Chlorophyllin Promotes the Growth of Wheat Roots Involved in Auxin and NO Action}

The positive influence of the Fe-chlorophyllin treatments on the growth of wheat root is obvious. Since nitric oxide has also been reported to be required for seedling wheat roots to develop [11], we were interested in testing the role of Fe-chlorophyllin in regulating nitric oxide generation. Recently, several studies have indicated that low levels of nitric oxide are able to mediate auxin controlled lateral root development $[12,13]$. Therefore, indole-3-acetic acid (IAA) oxidase and nitric oxide generation were measured in this paper.

IAA is one of the auxins that regulate plant growth and development as a plant hormone. The IAA oxidase has been suggested to play a crucial role in auxin metabolism. Evidently, the function of the enzyme is to regulate the growth of the plant by adjusting the hormonal level of IAA.

The effect of Fe-chlorophyllin on IAA oxidase activity in wheat seedling roots was investigated. As shown in Figure 3, a Fe-chlorophyllin concentration-dependent change in the activity of IAA oxidase was observed. IAA oxidase activity decreased with all treatments of Fe-chlorophyllin from 0.01 to $10 \mathrm{mg} / \mathrm{L}$. At the relatively low Fe-chlorophyllin concentration of $0.1 \mathrm{mg} / \mathrm{L}$, the activity of IAA oxidase was remarkably decreased, being $40.1 \%$ lower than the control.

Figure 3. Effects of Fe-chlorophyllin on the activity of IAA oxidase in the root of wheat. Seeds of wheat were soaked in the same culture solution containing $0,0.01,0.1,1$ and $10 \mathrm{mg} / \mathrm{L} \mathrm{Fe}$-chlorophyllin for $12 \mathrm{~h}$ and then transferred to the quarter-strength Hoagland's nutrient solution containing different concentrations of Fe-chlorophyllin for four days after germination. Vertical bars represent standard deviation of the mean $(n=3)$. Asterisks indicate that mean values are significantly different between the treatment and control $(p<0.05)$.

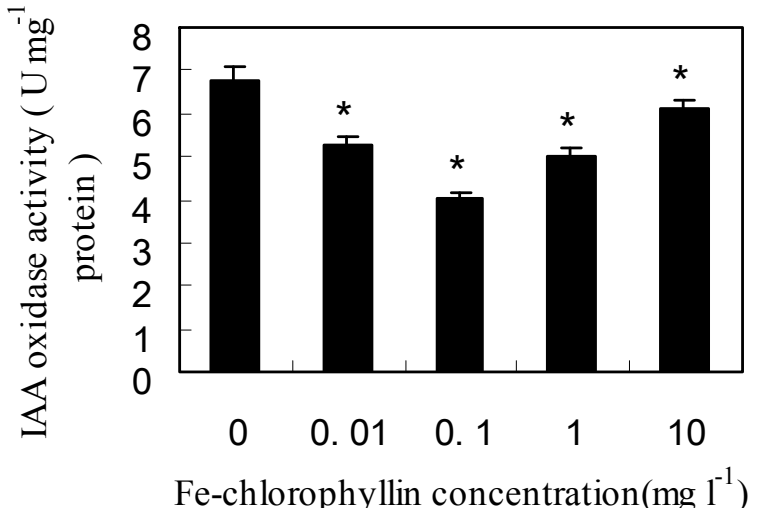

Nitric oxide is a biologically active gaseous molecule and is proposed to be one of the important second messengers in plant cells [14]. To confirm whether Fe-chlorophyllin-regulation of root growth dependent on nitric oxide action or not, the production of nitric oxide in wheat roots was detected using DAF-2DA fluorescent emission. The control (no Fe-chlorophyllin) root displayed only very light nitric oxide staining intensity around the root apex region, while roots exposed to Fe-chlorophyllin at $0.1 \mathrm{mg} / \mathrm{L}$ stained extensively (Figure 4). The intensity of fluorescent in $0.1 \mathrm{mg} / \mathrm{L}$ was near that observed for the positive control sodium nitroprusside (SNP), the nitric oxide donor. Thus, we speculated that Fe-chlorophyllin-regulation of root growth is associated with nitric oxide generation. 
Figure 4. Visualization of nitric oxide generation in primary wheat roots in vivo. Seeds were soaked with sodium nitroprusside (SNP; $100 \mu \mathrm{mol} / \mathrm{L}$ ) or Fe-chlorophyllin at $0,0.01$, $0.1,1$ and $10 \mathrm{mg} / \mathrm{L}$ for $12 \mathrm{~h}$ and then transferred to the quarter-strength Hoagland's nutrient solution containing different concentrations of Fe-chlorophyllin for four days after germination. The seedling roots were loaded with $15 \mu \mathrm{M}$ 4,5-diaminofluorescence (DAF-2DA) for $15 \mathrm{~min}$ and immediately photographed (bar $=0.5 \mathrm{~mm})$.

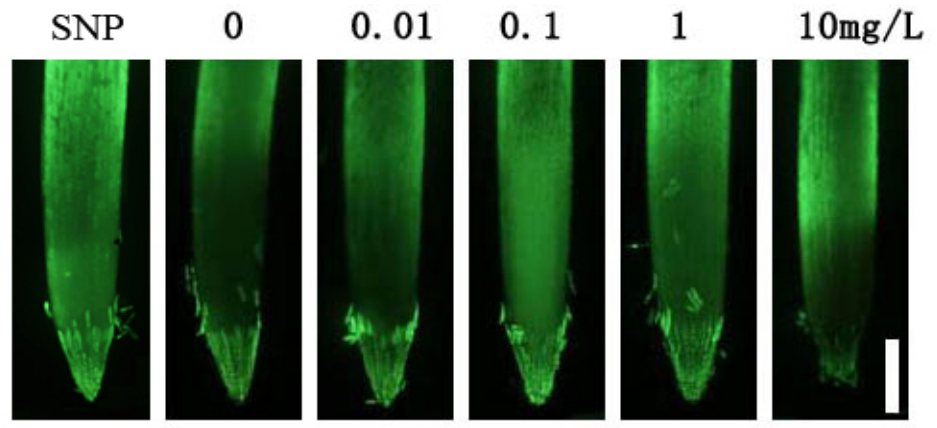

Nitric oxide plays various physiological roles in both plants and animals. Nitric oxide can enhance crop performance at any stage of its development including sowing, growth, flowering, and fruit formation or during many processes associated with the handling of the culture, such as transplantation, root formation in stem cuttings, or any other handling that could involve an oxidative stress condition for the plant. Nitric oxide might function downstream of the signal molecules of CO action by the maintenance of ion homeostasis and up-regulation of antioxidant defense in wheat seedling root tissues [15]. Hemin is the donor of $\mathrm{CO}$ in animals and plants [16,17]. We found that the structure of Fe-chlorophyllin and hemin are very similar, as shown in Figures 5a and 5b. We speculate that Fe-chlorophyllin, with the similar structure to hemin, could stimulate the production of the downstream signaling molecule nitric oxide. It is known that hemin is a useful plant growth regulator. It can enhance crop performance by application via soaking of seeds, spraying or irrigating [18]. The mechanism by which Fe-chlorophyllin promotes the growth of wheat roots will be further studied in our laboratory. Whether Fe-chlorophyllin is the donor of $\mathrm{CO}$ or not needs to be confirmed.

Figure 5. Structure of (a) hemin; and (b) Fe-chlorophyllin. $\mathrm{R}^{1}=\mathrm{H}, \mathrm{CH}_{3}$ or $\mathrm{CH}_{2} \mathrm{COOH}$; $\mathrm{R}^{2}=\mathrm{COOH}$; or $\mathrm{R}^{1}, \mathrm{R}^{2}=-\mathrm{CH}(\mathrm{COOH}) \mathrm{C}(\mathrm{O})-$.

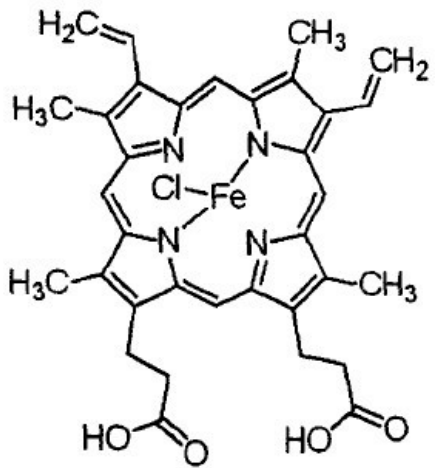

(a)

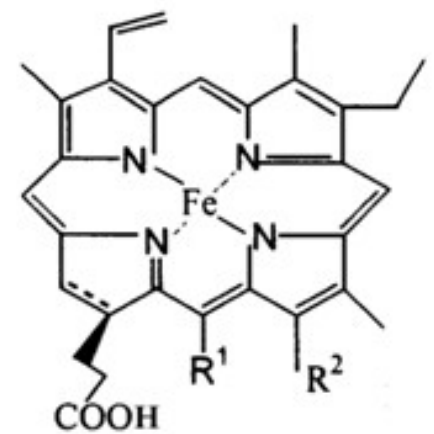

(b) 


\section{Experimental Section}

\subsection{Materials and Growth Conditions}

Fe-chlorophyllin was obtained from the Chlorophyll Factory of Hangzhou Electrochemical Group Co., Ltd. Seeds of wheat (Triticum aestivum L. Zhenmai) were sterilized with $0.1 \% \mathrm{HgCl}_{2}$, rinsed several times with distilled water, soaked in distilled water containing various concentrations of Fe-chlorophyllin $(0,0.01,0.1,1,10 \mathrm{mg} / \mathrm{L})$ for $12 \mathrm{~h}$ and germinated at $25^{\circ} \mathrm{C}$ in the dark. After germination, seedlings were transferred to the quarter-strength Hoagland's nutrient solution containing $0,0.01,0.1,1$, or $10 \mathrm{mg} / \mathrm{L}$ Fe-chlorophyllin, and grown at $24 \pm 1{ }^{\circ} \mathrm{C}$ with $100 \mu \mathrm{mol} \mathrm{m} \mathrm{m}^{-2} \mathrm{~s}^{-1}$ light intensity, and a $12 \mathrm{~h}$ photoperiod. Treatment solutions were changed daily. When the average root length was about 5-6 cm, the roots of seedlings were harvested and immediately frozen in liquid nitrogen and stored in $\mathrm{a}-70{ }^{\circ} \mathrm{C}$ freezer for further analysis.

\subsection{Enzyme Activity Assays}

Root tissues $(1.0 \mathrm{~g})$ were homogenized in $10 \mathrm{~mL}$ of ice-cold extraction buffer $(50 \mathrm{mM}$ Tris- $\mathrm{HCl}$, $\mathrm{pH}$ 7.8, $1 \mathrm{mM}$ EDTA, $1 \mathrm{mM} \mathrm{MgCl}_{2}$ and $1.5 \% \mathrm{w} / \mathrm{w}$ polyvinylpyrrolidone). The homogenate was centrifuged at $15,000 \mathrm{~g}$ for $20 \mathrm{~min}$ at $4{ }^{\circ} \mathrm{C}$. The supernatant was used as the crude extract to assay enzyme activities.

Analysis of guaiacol peroxidase (POD, EC 1.11.1.7) activity was based on oxidation of guaiacol using hydrogen peroxide [19]. The reaction mixture contained $2.5 \mathrm{~mL}$ of $50 \mathrm{mM}$ potassium phosphate buffer ( $\mathrm{pH}$ 6.1), $1 \mathrm{~mL}$ of $1 \%$ hydrogen peroxide, $1 \mathrm{~mL}$ of $1 \%$ guaiacol and 10-20 $\mu \mathrm{L}$ enzyme extract. The increase in absorbance at $420 \mathrm{~nm}$ was recorded. Activity was calculated using the extinction coefficient $\left(26.6 \mathrm{mM}^{-1} \mathrm{~cm}^{-1}\right)$. One unit of POD activity was defined as the amount needed to oxidize $1 \mu \mathrm{mol}$ guaiacol $\mathrm{min}^{-1}$ under the assay conditions.

Activity of superoxide dismutase (SOD, EC 1.1.5.1.1) was assayed by measuring the inhibition of photochemical reduction of nitro-blue tetrazolium (NBT) [20]. The reaction mixture (3 $\mathrm{mL})$ contained $50 \mathrm{mM}$ potassium phosphate buffer $(\mathrm{pH} 7.8), 10 \mathrm{mM}$ methionine, $1.17 \mathrm{mM}$ riboflavin and $56 \mathrm{mM}$ NBT and $50 \mu \mathrm{L}$ enzyme extract. The absorbance of the solution was measured at $560 \mathrm{~nm}$. One unit of SOD was defined as the amount of enzyme causing half-maximal inhibition of the NBT reduction under the assay conditions.

\subsection{Gel Electrophoresis}

The isoenzymes of peroxidase and superoxide dismutase were separated on discontinuous polyacrylamide gels (stacking gel 5\% and separating gel 10\%) under non-denaturing conditions. Proteins were electrophoresed at $4{ }^{\circ} \mathrm{C}$ and $10 \mathrm{~mA}$ in the stacking gel followed by $15 \mathrm{~mA}$ in the separating gel. One gram of root tissue was homogenized with $50 \mathrm{mM}$ potassium phosphate buffer (pH 7.0) including $1 \mathrm{mM}$ 2-mercaptoethanol, $0.5 \mathrm{mM}$ phenylmethyl, $2 \mathrm{mM}$ EDTA. The homogenate was centrifuged at $15,000 \mathrm{~g}$ for $20 \mathrm{~min}$ at $4{ }^{\circ} \mathrm{C}$. The supernatant was used for detection of isoenzymes.

Superoxide dismutase activity was determined on the gel as described by [21]. The gels were rinsed in water and incubated in the dark for $30 \mathrm{~min}$ at room temperature in an assay mixture containing 
$50 \mathrm{mM}$ potassium phosphate buffer ( $\mathrm{pH} 7.8$ ), $1 \mathrm{mM}$ EDTA, $0.05 \mathrm{mM}$ riboflavin, $0.1 \mathrm{mM}$ nitroblue tetrazolium and $0.3 \% \quad N, N, N^{\prime}, N^{\prime}$-tetramethylethylenediamine (TEMED). After that, the gels were rinsed with water and exposed on a light box for $10 \mathrm{~min}$ at room temperature until the development of colorless bands of SOD activity in a purple-stained gel were visible. For peroxidase isoforms, the gels were stained for $20 \mathrm{~min}$ in $0.2 \mathrm{M}$ acetate buffer ( $\mathrm{pH}$ 5.5) with $5 \mathrm{mM}$ benzidine and $5 \mathrm{mM} \mathrm{H}_{2} \mathrm{O}_{2}$ [22].

\subsection{IAA Oxidase Assay}

For the IAA oxidase assay, the reaction mixture consisted of $0.66 \mathrm{mmol} / \mathrm{L} \mathrm{IAA}, 1 \mathrm{mmol} / \mathrm{L} \mathrm{MnCl}_{2}$, $0.1 \mathrm{mmol} / \mathrm{L} p$-coumaric acid, $50 \mathrm{mmol} / \mathrm{L} \mathrm{Na}$-phosphate $(\mathrm{pH} \mathrm{5.7)}$ and enzyme extract. The reaction was monitored by following the change in absorbance at $260 \mathrm{~nm}$. IAA oxidase activity was estimated as $\triangle A 260 \mathrm{~nm} \mathrm{~min}{ }^{-1}$ at $25^{\circ} \mathrm{C}[23]$.

\subsection{Detection of Intracellular Nitric Oxide}

Detection of root cellular nitric oxide was performed by the method described by Correa-Aragunde et al. [12]. Seeds of wheat were soaked in distilled water containing various concentrations of Fe-chlorophyllin. After germination, seedlings were transferred to the quarter-strength Hoagland's nutrient solution containing various concentrations of Fe-chlorophyllin. When the average root length was about 5-6 cm, the roots of seedlings were transferred to $20 \mathrm{mM} H E P E S-N a O H$ ( $\mathrm{pH}$ 7.5) buffer solution containing $15 \mu \mathrm{M}$ specific nitric oxide fluorescent probe 4,5-diaminofluorescein diacetate (DAF-2DA). After incubation in the dark for $15 \mathrm{~min}$, the roots were washed several times and immediately visualized (excitation $490 \mathrm{~nm}$ and emission $525 \mathrm{~nm}$ ) using a fluorescence microscope (ECLIPSE 80i, Nikon).

\subsection{Statistical Analysis}

Each result shown in the figures is the mean of at least three replicated treatments. The significance of the differences between treatments was statistically evaluated by standard deviation and Student's $t$-test methods.

\section{Conclusion}

Fe-chlorophyllin has antioxidant ability in mammals. In this paper, we found that it could also increase the activities of reactive oxygen scavenging enzyme, and promote the growth of wheat roots. Furthermore, Fe-chlorophyllin could enhance intracellular nitric oxide generation and decrease the IAA oxidase activity in roots. Nitric oxide is one of the important second messengers in plant cells. The function of IAA oxidase is to regulate the growth of the plant by adjusting the hormonal level of IAA. The mechanism by which Fe-chlorophyllin enhances intracellular nitric oxide needs to be further elucidated. 


\section{Acknowledgements}

This research was supported by the Postdoctoral Special Foundation of China (No. 200902524) and Natural science fund for colleges and universities in Jiangsu Province (No. 09KJD180001). The authors are grateful to Langlai Xu in Nanjing Agricultural University for helpful advice and discussions.

\section{References}

1. Gill, S.S.; Tuteja, N. Reactive oxygen species and antioxidant machinery in abiotic stress tolerance in crop plants. Plant Physiol. Biochem. 2010, 48, 909-930.

2. Schoneich, C. Reactive oxygen species and biological aging: a mechanistic approach. Exp. Gerontol. 1999, 34, 19-34.

3. Halliwell, B. Reactive species and antioxidants. Redox biology is a fundamental theme of aerobic life. Plant Physiol. 2006, 141, 312-322.

4. Chernomorsky, S.; Rancourt, R.; Virdi, K.; Segelman, A.; Poretz, R.D. Antimutagenicity, cytotoxicity and composition of chlorophyllin copper complex. Cancer Lett. 1997, 120, 141-147.

5. Chung, W.Y.; Lee, J.M.; Park, M.Y.; Yook, J.I.; Kim, J.; Chung, A.S.; Surh, Y.J.; Park, K.K. Inhibitory effects of chlorophyllin on 7,12-dimethylbenz anthracene-induced bacterial mutagenesis and mouse skin carcinogenesis. Cancer Lett. 1999, 145, 57-64.

6. Kamat, J.P.; Boloor, K.K.; Devasagayam, T.P.A. Chlorophyllin as an effective antioxidant against membrane damage in vitro and ex vivo. Biochim. Biophys. Acta 2000, 1487, 113-127.

7. Sato, M.; Fujimoto, I.; Sakai, T.; Aimoto, T.; Kimura, R.; Murata, T. Effect of Sodium Copper Chlorophyllin on Lipid Peroxidation. IV. The Antioxidative Action of Copper Chlorins. Chem. Pharm. Bull. 1986, 34, 2428-2434.

8. Inoue, H.; Yamashita, H.; Furuya, K.; Nonomura, Y.; Yoshioka, N.; Li, S. Determination of copper(II) chlorophyllin by reversed-phase high-performance liquid chromatography. J. Chromatogr. A 1994, 679, 99-104.

9. Arimoto, S.; Kan-yama, K.; Rai, H.; Hayatsu, H. Inhibitory effect of hemin, chlorophyllin and related pyrrole pigments on the mutagenicity of benzo pyrene and its metabolites. Mutat. Res. 1995, 345, 127-135.

10. Liu, K.; Xu, S.; Xuan, W.; Ling, T.; Cao, Z.; Huang, B.; Sun, Y.; Fang, L.; Liu, Z.; Zhao, N.; et al. Carbon monoxide counteracts the inhibition of seed germination and alleviates oxidative damage caused by salt stress in Oryza sativa. Plant Sci. 2007, 172, 544-555.

11. Chen, M.; Shen, W.B.; Ruan, H.H.; Xu, L.L. Effects of Nitric Oxide on Root Growth and Its Oxidative Damage in Wheat Seedling Under Salt Stress. J. Plant Physiol. Mol. Biol. 2004, 30, 569-576.

12. Correa-Aragunde, N.; Graziano, M.; Lamattina, L. Nitric oxide plays a central role in determining lateral root development in tomato. Planta 2004, 218, 900-905.

13. Correa-Aragunde, N.; Graziano, M.; Chevaller, C.; Lamattina, L. Nitric oxide modulates the expression of cell cycle regulatory genes during lateral root formation in tomato. J. Exp. Bot. 2006, 57, 581-588.

14. Durner, J.; Klessig, D.F. Nitric oxide as a signal in plants. Curr. Opin. Plant Biol. 1999, 2, 369-374. 
15. Xie, Y.J.; Ling, T.F.; Han, Y.; Liu, K.L.; Zheng, Q.S.; Huang, L.Q.; Yuan, X.X.; He, Z.; Hu, B.; Fang, L.; et al. Carbonmonoxide enhances salt tolerance by nitric oxide-mediated maintenance of ion homeostasis and up-regulation of antioxidant defense in wheat seedling roots. Plant Cell Environ. 2008, 66, 2494-2498.

16. Longo, M.; Jain, V.; Vedernikov, Y.P.; Saade, G.R.; Goodrum, L.; Facchinetti, F.; Garfield, R.E. Effect of nitric oxide and carbon monoxide on uterine contractility during human and rat pregnancy. Am. J. Obstet. Gynecol. 1999, 181, 981-988.

17. Xu, J.; Xuan, W.; Huang, B.K.; Zhou, Y.H.; Ling, T.F.; Xu, S.; Shen, W.B. Carbon monoxideinduced adventitious rooting of hypocotyl cutting from mung bean seedling. Chin. Sci. Bull. 2006, 51, 668-674.

18. Shen, W.; Huang, L.; Shen, J.; Ling, T.; Xuan, W.; Xu, S.; Ye, M.; Shao, S.; Huang, B.; Gu, K.; et al. A Plant Growth Regulator Containing Hemin. Chin. Patent 200610097240.3, 28 March 2007.

19. Upadhyaya, A.D.; Sankhla, T.D.; Davis, N.; Sankhla, B.N.; Smith, J. Effect of paclobutrazol on the activities of some enzymes of activated oxygen metabolism and lipid peroxidation in senescing soybean leaves. J. Plant Physiol. 1985, 121, 453-461.

20. Beauchamp, C.; Fridovich, I. Superoxide dismutase: improved assays and an assay applicable to acrylamide gels. Anal. Biochem. 1971, 44, 276-287.

21. Pereira, G.J.G.; Molina, S.M.G.; Lea, P.J.; Azevdo, R.A. Activity of antioxidant enzymes in response to cadmium in Crotalaria juncea. Plant Soil 2002, 239, 123-132.

22. Janda, T.; Szalai, G.; Tari, I.; Paldi, E. Hydroponic treatment with salicylic acid decreases the effects of chilling injury in maize (Zea mays L.) plants. Planta 1999, 208, 175-180.

23. Milrad de Forchetti, S.; Tigier, H.A. Effect of dicarboxylic acids on the peroxidase-IAA oxidase isozymes of soybean callus. Physiol. Plant. 1983, 59, 355-358.

(C) 2010 by the authors; licensee MDPI, Basel, Switzerland. This article is an open access article distributed under the terms and conditions of the Creative Commons Attribution license (http://creativecommons.org/licenses/by/3.0/). 